\title{
Midwifery students' experiences of an innovative clinical placement model embedded within midwifery continuity of care in Australia
}

\section{Abstract \\ Background}

Midwifery continuity of care experiences can provide high quality clinical learning for students but can be challenging to implement. The Rural and Private Midwifery Education Project (RPMEP) is a strategic government funded initiative to (1) grow the midwifery workforce within private midwifery practice and rural midwifery, by (2) better preparing new graduates to work in private midwifery and rural continuity of care models.

\section{Aim}

This study evaluated midwifery students' experience of an innovative continuity of care clinical placement model in partnership with private midwifery practice and rural midwifery group practices.

\section{Method}

A descriptive cohort design was used. All students in the RPMEP were invited to complete an online survey about their experiences of clinical placement within midwifery continuity models of care. Responses were analysed using descriptive statistics. Correlations between total scale scores were examined. Open-ended responses were analysed using content analysis. Internal reliability of the scales was assessed using Cronbach's alpha.

\section{Results}

Sixteen out of 17 completed surveys were received (94\% response rate). Scales included in the survey demonstrated good internal reliability. The majority of students felt inspired by caseload approaches to care, expressed overall satisfaction with the mentoring received and reported a positive learning environment at their placement site. Some students reported stress related to course expectations and demands in the clinical environment (e.g. skill acquisition and hours required for continuity of care). There were significant correlations between scales on perceptions of caseload care and learning culture $(r=.87 \mathrm{p}<.001)$ and assessment $(r=.87 \mathrm{p}<.001)$. Scores on the clinical learning environment scale were significantly correlated with perceptions of the caseload model (rho $=.86 \mathrm{p}<.001$ ), learning culture $($ rho $=.94 \mathrm{p}<.001)$ and assessment $($ rho $=.65 \mathrm{p}<.01)$ scales. 


\section{Conclusions}

Embedding students within midwifery continuity of care models was perceived to be highly beneficial to learning, developed partnerships with women, and provided appropriate clinical skills development required for registration, while promoting students' confidence and competence. The flexible academic program enabled students to access learning at any time and prioritise continuity of care experiences. Strategies are needed to better support students achieve a satisfactory work-life balance.

Keywords: Midwifery students, satisfaction, clinical learning, continuity of care, midwifery education, follow through experience 


\section{Introduction}

In Australia, the National Maternity Services Plan 2012-2013 (Australian Health Ministers' Advisory Council, 2011) outlined the Government's intent to increase access to midwifery led models of care and utilise midwives to their full scope of practice. This major maternity services reform to expand women's access to primary midwife-led continuity of care (CoC) is underpinned by high quality evidence that shows positive outcomes for mothers and babies (Hatem et al 2008; Sandall et al, 2013). Midwifery students currently undertake CoC experiences in Australia (Gray et al 2012; McLachlan et al, 2013; Sweet \& Glover, 2013; Clements et al., 2013), Norway (Aune et al., 2011), New Zealand (NZCOM) and the United Kingdom (Fry et al., 2008; Lewis et al., 2008; Rawnson et al., 2009; Rawnson 2011). However there is little evidence to guide the quantity and scope of continuity of care experiences undertaken by students. Ongoing evaluative data about students' CoC experiences is required. This paper reports on a survey conducted with a cohort of midwifery students to evaluate an innovative embedded continuity of care clinical placement model offered in partnership with midwifery private and rural group practices.

\section{Continuity of care experiences}

Continuity of care experiences (also known as follow-through or caseload care) require midwifery students to form partnerships with women throughout pregnancy, childbirth and postnatal care. In Australia the accreditation body mandates that students undertake a minimum of twenty CoC experiences with an average of 20 hours per woman (ANMAC, 2010). Students' practice during the continuity experience is supervised. However, many practical challenges associated with $\mathrm{CoC}$ are evident. For example, the majority of maternity services in Australia continue to provide fragmented models of care limiting opportunities for midwifery students to experience $\mathrm{CoC}$ in practice and learn from professional role models. Furthermore, students are often required to independently recruit and follow women in their own time, in whichever clinical setting is chosen by the woman.

An evaluation study in Australia by Gray, et al. (2012) found that while current students ( $\mathrm{n}=$ 93) and graduates $(n=8)$ of a direct entry three-year Bachelor of Midwifery were positive about opportunities to develop relationships with women, some aspects of the follow-through experience were difficult. Students were challenged by the need to recruit women and find time to fully engage with them. University-based support to undertake $\mathrm{CoC}$ experiences was often lacking and program requirements for documentation about $\mathrm{CoC}$ varied. Similarly in a 
state-wide online survey of students $(n=401)$ and academics $(n=35)$ in Victoria, McLachlan et al. (2013) reported that while the follow-through experience was considered to be unique and valuable, respondents raised major concerns. Students often missed lectures/tutorials as well as designated clinical placements because of the need to spend extensive periods of time oncall both during and outside the university semester timetable. Students and academics also reported concerns about the impact of follow-through experiences on students' personal lives, including diminished opportunities for paid employment and family responsibilities (such as childcare or caring for family members) (McLachlan et al., 2013).

Recently, in a qualitative evaluation of the continuity of care experience of midwifery students in one Australian university, Sweet and Glover (2013) found that although a professional relationship formed between midwifery students and supervising clinicians, this relationship was not always optimal. Students often perceived themselves to be observers and complained of not belonging to the health care team, and having no real role to play. Similar findings have been reported in other studies (e.g., Seibold, 2005; McKenna and Rolls, 2007). In the UK, many programs delay students' experience of holding their own caseload by 18 months, to enable prerequisite skill development (Lewis et al., 2008; Rawnson et al., 2008).

In terms of the student-woman relationship, Rawnson (2011) found that students had an overwhelming desire and concern to meet and facilitate women's expectations. Perceptions of letting the woman down evoked feelings of inadequacy and failure. On-call commitment and carrying a caseload alongside academic and home commitments were emotionally stressful. Carolan-Olah et al. (2014) reported similar concerns by completing midwifery students $(n=10)$ which contributed to a lack of confidence and poorer integration and socialisation into the profession. Gray et al. (2013) concluded that challenges associated with $\mathrm{CoC}$ experiences need to be addressed at a systematic level and new strategies need to be developed to embed students in $\mathrm{CoC}$ models rather than just completing the required $20 \mathrm{CoC}$ experiences.

In order to address the shortcomings of existing clinical models in midwifery education and build midwifery workforce capacity, a project funded by a state health department in collaboration with the university sector and clinical agencies was designed to place midwifery students in continuity models of care for the duration of their degree program. A multi-phase evaluation project was undertaken. This paper reports on students' perceptions of their $\mathrm{CoC}$ practicum after 12 months of their two year program. 


\section{Description of the project}

The Rural and Private Midwifery Education Project (RPMEP) is a strategic initiative to grow the midwifery workforce and better prepare new midwifery graduates to work in private midwifery practices and rural midwifery continuity models of care. This project was funded by the Department of Health through the Nursing and Midwifery Office Queensland (NMOQ). A private midwifery group practice called My Midwives was contracted to manage this project and Griffith University was chosen through a tender process as the preferred education provider (for Cohort 1).

NMOQ determined the criteria for student applications. Expressions of interest were sought from recent graduates with a Bachelor of Nursing who had not secured full time employment within one year of graduation, and had a specific interest in midwifery/women's health. My Midwives interviewed and selected candidates who then enrolled in a Bachelor of Midwifery (BMid) program. The BMid program is designed around a philosophy of woman-centred care and incorporates reflection and development of critical thinking at each year level. The degree is delivered in blended mode, which involves a combination of face-to-face intensive teaching, interactive on-line material including "real time" webinars (web-based discussions), supervised clinical practice, and lecturer-led face-to-face tutorials offered in clinical sites. Fifty percent of curriculum hours are committed to clinical education. Students are required to complete at least 20 continuity of care experiences which are inclusive of a minimum of five antenatal visits, attendance at the birth and three postnatal visits (one of which is at six weeks postpartum). The flexible delivery of the BMid program enables students to prioritise their continuity of care experiences with women. This curriculum feature has been consistently reported by students as paramount to their developing sense of purpose and identity as a midwife (Sidebotham et al, 2014). As RPMEP students possessed a Bachelor of Nursing, they received 80 credit points for prior learning (equivalent to one year of full-time study). RPMEP students were therefore able to complete the BMid in 2 years of full-time study. Under the conditions of the RPMEP, course fees were paid by the government. Students received an education allowance of around $\$ 6000$ AUS per quarter to offset living expenses as many were required to relocate to undertake the program. The allowance enabled students to focus on $\mathrm{CoC}$ experiences without undertaking part-time work whilst studying.

Within the usual BMid program students are placed at one clinical site (a hospital) for their entire program and undertake clinical placement for two days per week. In contrast, RPMEP students were placed in either midwifery private practices or rural midwifery group practices 
that offered services to all-risk women. In addition, a small number of hospital shifts were undertaken to meet learning requirements associated with complex clinical care (e.g. neonatal nursery experience, surgical experience).

\section{Method}

A descriptive cohort design was used to survey students about their $\mathrm{CoC}$ practicum after 12 months.

\section{Sample}

All students currently enrolled in the RPMEP $(n=17)$ were invited to participate. All participants were female. Ages ranged from 22-50 years, with a mean age of 25.8 years. All have tertiary level education, with $100 \%$ of students having completed a Bachelor of Nursing and one student additionally having completed a Graduate Diploma of Public Health.

\section{Measures}

The survey consisted of six sections. Section one asked about the model of care in which students predominantly worked. Remaining sections contained scales to investigate aspects of the clinical program. Scale items were developed from a critical review of the literature; a critique of any existing measures; discussions with midwifery educators and clinicians; and from the expertise of the evaluation team. Survey content was reviewed by an expert panel (n =7) consisting of two clinicians, four midwifery academics, and a psychologist for clarity and validity.

All scales required responses on a five-point Likert scale that ranged from $1=$ strongly disagree to 5=strongly agree. Section two was an eight-item scale on students' perceptions of working in caseload models of care and included statements such as, 'I feel inspired by this model of care' and 'enabled me to establish a partnership model with women'. Section three contained 8 items on the student/mentor relationship. Students responded to items such as, 'I received individual mentoring during my clinical practice' and 'the mentoring relationship was characterised by trust'. Section four consisted of 8 items that sought feedback on the clinical learning culture; and Section five had 4 items that measured perceptions of assessment processes to determine competence to practice. Section six asked a question about future employment intentions. Students could provide additional free-text at the end of each section.

\section{Approach to analysis}

Descriptive statistics are reported as well as total scale scores. Internal reliability of each scale 
was assessed using Cronbach's alpha. Tests of homogeneity of variance were conducted to determine if parametric (Pearson's correlation) or non-parametric (Spearman's rho) tests would be used to determine correlations among scale scores. Qualitative data is used to illustrate the survey findings.

\section{Procedure}

The revised questionnaire was uploaded online using LimeSurvey software. Students were sent a link to the survey via email and invited to participate in the study. The survey was conducted in July 2014 and two reminders were sent over a four week period. All survey responses were anonymous. Students were advised that data would be collected and analysed by a researcher not involved in theoretical or clinical components of the RPMEP to encourage participation and open disclosure. Approval was obtained from the University's Human Research Ethics committee.

\section{Results}

Sixteen out of a possible 17 students responded to the survey ( $94 \%$ response rate). One student did not complete all sections, but was retained, and therefore the number of respondents for each scale varies. After 12 months into the 24 month program, students had completed an average of 13 continuity of care experiences (range 8 to 22). Students anticipated no difficulties completing the minimum 20 continuity of care experiences by the conclusion of their program of study.

\section{Section 1: Model of care}

Seven students were placed in a private midwifery group practice, two in a sole practitioner private practice, and seven in a rural hospital Midwifery Group Practice. In private practice the same midwife provides continuity of care for a woman through pregnancy, labour and birth, and postpartum. Midwifery Group Practice (MGP) is described as the primary midwifery care provider offering continuity of care to a woman with the support of up to two other midwives.

\section{Section 2: Perceptions of working in a caseload model}

This eight-item scale had good internal reliability (Cronbach's alpha $=.82$ ). The mean score was $31.68(\mathrm{SD}=5.34)$ out of a possible 40 . The majority $(93.8 \%)$ of students were inspired by caseload approaches to care. Furthermore, most $(n=13,81.3 \%)$ felt fulfilled working in caseload models but two disagreed and one student was unsure. Students disagreed $(56.3 \%)$ 
or were uncertain $(25 \%)$ that they could achieve a satisfactory work/life balance when working in a caseload model. Students articulated their commitment to $\mathrm{CoC}$, but also expressed concerns about the impact of this model on other aspects of life: I love continuity of care, and feel that it is now engrained within my soul. However, I continuously see myself and the midwives I work with being overrun with unmanageable work/life/study balance, and I am unsure of how this will fit in to my life in the future (Student 4).

I desperately want to work within continuity of care when I finish my course, but I will endeavour to fulfil a more appropriate work life balance (Student 5).

In their role as a student midwife, respondents strongly agreed $(68.8 \%)$ / agreed $(31.3 \%)$ that they were learning a great deal about midwifery from working in caseload models. All students felt they had developed specific skills necessary to work in this model of care (56.3\% strongly agreed; $43.8 \%$ agreed).

While many students $(n=10 ; 62.5 \%)$ agreed that working in caseload models would enable them to meet all their clinical learning requirements, two were unsure and four disagreed. Thirteen students $(81.3 \%$ ) felt confident they would be able to perform the full range of clinical skills required for registration, but two were unsure and one disagreed. Nearly twothirds $(62.6 \%)$ of students strongly agreed/ agreed that any issues related to their clinical placement were addressed in a timely manner, but six (37.5\%) were unsure.

Table 1 - Student responses: Perceptions of working in a caseload model $(n=16)$

\begin{tabular}{|l|l|l|l|l|c|}
\hline Item & $\begin{array}{l}\text { Strongly } \\
\text { agree }\end{array}$ & Agree & Neutral & Disagree & $\begin{array}{l}\text { Strongly } \\
\text { Disagree }\end{array}$ \\
\hline Feel inspired by this approach to care & $9(56.3)$ & $6(37.5)$ & $1(6.3)$ & - & - \\
\hline $\begin{array}{l}\text { Feel fulfilled working in this model } \\
\text { of care }\end{array}$ & $7(43.8)$ & $6(37.5)$ & $1(6.3)$ & $2(12.5)$ & - \\
\hline $\begin{array}{l}\text { Learn a great deal about midwifery } \\
\text { from working in this model }\end{array}$ & $11(68.8)$ & $5(31.3)$ & - & - & - \\
\hline $\begin{array}{l}\text { Develop specific skills to work in } \\
\text { this model of care }\end{array}$ & $9(56.3)$ & $7(43.8)$ & - & - & - \\
\hline $\begin{array}{l}\text { Fulfil all my clinical learning } \\
\text { requirements }\end{array}$ & $2(12.5)$ & $8(50)$ & $2(12.5)$ & $4(25)$ & - \\
\hline $\begin{array}{l}\text { Be able to perform the full range of } \\
\text { clinical skills }\end{array}$ & $3(18.8)$ & $10(62.5)$ & $2(12.5)$ & $1(6.3)$ & - \\
\hline $\begin{array}{l}\text { Placement issues are managed in a } \\
\text { timely manner }\end{array}$ & $5(31.3)$ & $5(31.3)$ & $6(37.5)$ & - & - \\
\hline $\begin{array}{l}\text { Achieve a satisfactory work / study / } \\
\text { life balance }\end{array}$ & - & $3(18.8)$ & $4(25)$ & $6(37.5)$ & $3(18.8)$ \\
\hline
\end{tabular}




\section{Section 3: Perceptions of the student/ mentor relationship}

This eight-item scale had good internal reliability (Cronbach alpha $=.95)$. The mean score was $34.27(\mathrm{SD}=4.07)$ out of a possible 40. Mentor relationships varied across the group. A third of students $(n=5 ; 31.3 \%)$ worked closely with a mentor, while remaining students were supervised by a small group ( 2 to 3 ) of midwives. Two students had no primary mentor and reported being supervised by 4 or more different midwives.

There was a high level of satisfaction with the mentorship received during the clinical program. Their responses on the scale revealed the majority of students $(n=14,87.5 \%)$ consistently strongly agreed/ agreed that they received individual mentoring/supervision during their placement. Similarly, the majority of students $(n=14,87.5 \%)$ strongly agreed/ agreed to the presence of mutual respect and approval in the mentor/supervisory relationship, a sense of equality that promoted learning; and that the mentoring relationship was characterised by a sense of trust. Although many students $(n=11,68.8 \%)$ reported receiving continuous feedback from their mentor, four students were unsure. Of the 15 out of the 16 students that completed this section, all students $(n=15,93.8 \%)$ reported their mentor/supervisor demonstrated a positive attitude toward their role, and expressed satisfaction with the mentoring/supervision received. One student wrote: I love this mentor program far more than the placements I experienced in my nursing training. Far more conducive to learning!!! (Student 6). Another wrote: I have thoroughly enjoyed working closely with a midwife. I feel that this model of teaching benefits the student, the midwife and the women. The mentor program allows for good rapport and the development of a relationship that works on trust, feedback and autonomy (Student 3). 
Table 2- Student responses: Perceptions of the student/mentor relationship $(n=15)$

\begin{tabular}{|l|l|l|l|l|c|}
\hline Item & $\begin{array}{l}\text { Strongly } \\
\text { agree }\end{array}$ & Agree & Neutral & Disagree & $\begin{array}{c}\text { Strongly } \\
\text { Disagree }\end{array}$ \\
\hline $\begin{array}{l}\text { I received individual mentoring / } \\
\text { supervision during my placement }\end{array}$ & $6(37.5)$ & $8(50)$ & $1(6.3)$ & - & - \\
\hline $\begin{array}{l}\text { There was mutual interaction in the } \\
\text { mentor / supervisory relationship }\end{array}$ & $5(31.3)$ & $9(56.3)$ & $1(6.3)$ & - & - \\
\hline $\begin{array}{l}\text { Mentoring / supervision was based } \\
\text { on a relationship of equality that } \\
\text { promoted my learning }\end{array}$ & $6(37.5)$ & $8(50)$ & $1(6.3)$ & - & - \\
\hline $\begin{array}{l}\text { The mentoring / supervisory } \\
\text { relationship was characterised by a } \\
\text { sense of trust }\end{array}$ & $6(37.5)$ & $8(50)$ & $1(6.3)$ & - & - \\
\hline $\begin{array}{l}\text { Overall I am satisfied with the } \\
\text { mentoring / supervision I received }\end{array}$ & $5(31.3)$ & $\begin{array}{c}10 \\
(62.5)\end{array}$ & - & - & - \\
\hline $\begin{array}{l}\text { Mutual respect and approval } \\
\text { prevailed in the mentoring / } \\
\text { supervision relationship }\end{array}$ & $5(31.3)$ & $\begin{array}{c}10 \\
(62.5)\end{array}$ & - & - & - \\
\hline $\begin{array}{l}\text { I continuously received feedback } \\
\text { from my mentor / supervisor }\end{array}$ & $3(18.8)$ & $8(50)$ & $4(25)$ & - & - \\
\hline $\begin{array}{l}\text { My mentor / supervisor showed a } \\
\text { positive attitude towards their role }\end{array}$ & $6(37.5)$ & $9(56.3)$ & - & - & - \\
\hline
\end{tabular}

\section{Section 4: Learning culture}

This eight-item scale had good internal reliability (Cronbach alpha $=.92)$. The mean total score was $35.4(\mathrm{SD}=3.9)$ out of a possible 40. In general, the majority of students felt supported and positive about the clinical learning culture. For example, of the 15 out of 16 students who completed this section, all $(n=15,93.8 \%)$ of the students reported that it was easy to approach their mentor about issues, strongly agreed/ agreed that learning situations were holistic, involving all aspects of women's care and that the agency promoted a positive learning environment. Students reported experiencing sufficient meaningful learning situations during their placement $(n=14,87.6 \%)$; and felt comfortable going to clinical placement each day $(n=12,75.1 \%)$ although 3 students were unsure. Most students $(n=13$, $81.3 \%$ ) also felt confident taking part in discussions about a woman's care, but two students reported being unsure. Positive perceptions of the learning culture were also enhanced because students perceived a personal relationship with their mentor $(n=14,87.6 \%)$; and strongly agreed/ agreed their mentor was generally interested in student learning $(n=14$, 87.6\%). One student compared her experience of working with a $\mathrm{CoC}$ midwife with a previous hospital placement:

I felt that I was able to accept feedback a lot more easily. I am able to actively engage in my 
learning by asking questions at any point as I am working more on skill development as opposed to trying to ensure I am working the way "that midwife" likes, as you do when you are working in a hospital setting where you are placed with whoever is on shift (Student 4). Another student commented positively about her role:

My clinical site is highly conducive to learning and the culture is that I am part of the site not a student. I have been involved in every aspect of care, management and set up of the business and services that are available in our area (Student 13).

Table 3 - Student responses: Learning Culture $(n=15)$

\begin{tabular}{|l|l|l|l|l|c|}
\hline Item & $\begin{array}{l}\text { Strongly } \\
\text { agree }\end{array}$ & Agree & Neutral & Disagree & $\begin{array}{l}\text { Strongly } \\
\text { Disagree }\end{array}$ \\
\hline $\begin{array}{l}\text { My mentors / supervisors were easy } \\
\text { to approach }\end{array}$ & $7(43.8)$ & $8(50)$ & - & - & - \\
\hline $\begin{array}{l}\text { My mentors / supervisors developed } \\
\text { a personal relationship with me }\end{array}$ & $7(43.8)$ & $7(43.8)$ & $1(6.3)$ & - & - \\
\hline $\begin{array}{l}\text { I felt comfortable going to my } \\
\text { clinical practicum each day }\end{array}$ & $5(31.3)$ & $7(43.8)$ & $3(18.8)$ & - & - \\
\hline $\begin{array}{l}\text { I felt confident taking part in } \\
\text { discussions about a woman's care }\end{array}$ & $5(31.3)$ & $8(50)$ & $2(13.3)$ & - & - \\
\hline $\begin{array}{l}\text { My mentor / supervisors were } \\
\text { generally interested in student } \\
\text { learning }\end{array}$ & $9(56.3)$ & $5(31.3)$ & $1(6.3)$ & - & - \\
\hline $\begin{array}{l}\text { There were sufficient meaningful } \\
\text { learning situations during my } \\
\text { placement }\end{array}$ & $9(56.3)$ & $5(31.3)$ & $1(6.3)$ & - & - \\
\hline $\begin{array}{l}\text { The learning situations were holistic, } \\
\text { involving all aspects of women's care }\end{array}$ & $9(56.3)$ & $6(37.5)$ & - & - & - \\
\hline $\begin{array}{l}\text { My midwifery placement site } \\
\text { promoted a positive learning } \\
\text { environment }\end{array}$ & $8(50)$ & $7(43.8)$ & - & - & - \\
\hline
\end{tabular}

\section{Section 5: Perceptions of assessment}

This four item scale had modest internal reliability (Cronbach's alpha =.69) and a total score of $16.26(\mathrm{SD}=2.4)$ out of a possible 20. Fifteen students who completed this part of the survey reported positive perceptions of assessment, but indicated some areas for change. Many students $(n=11,68.8 \%)$ strongly agreed/ agreed the midwife they worked with was easily able to assess their progress through the course/program, but four students (25\%) were unsure. Most students also reported that it was straightforward to achieve the clinical requirements but 4 were unsure or disagreed. Keeping a clinical log was perceived as useful for students' professional career (75.1\%), and many (62.5\%) valued reflection as an 
important aspect of clinical learning but five (31.3\%) students were unsure.

Table 4 - Students' perceptions of assessment $(n=15)$

\begin{tabular}{|l|c|c|c|c|c|}
\hline Item & $\begin{array}{c}\text { Strongly } \\
\text { agree }\end{array}$ & Agree & Unsure & Disagree & $\begin{array}{c}\text { Strongly } \\
\text { disagree }\end{array}$ \\
\hline $\begin{array}{l}\text { Keeping a clinical log/portfolio is } \\
\text { useful for my professional career. }\end{array}$ & $3(18.8)$ & $9(56.3)$ & $3(18.8)$ & - & - \\
\hline $\begin{array}{l}\text { I value reflection as an important } \\
\text { aspect of clinical learning. }\end{array}$ & $6(37.5)$ & $4(25)$ & $5(31.3)$ & - & - \\
\hline $\begin{array}{l}\text { I found it straightforward to achieve } \\
\text { my clinical requirements in this } \\
\text { model }\end{array}$ & $7(43.8)$ & $4(25)$ & $3(18.8)$ & $1(6.3)$ & - \\
\hline $\begin{array}{l}\text { The midwife/midwives I worked } \\
\text { with were easily able to assess my } \\
\text { progress through the course /program }\end{array}$ & $5(31.3)$ & $6(37.5)$ & $4(25)$ & - & - \\
\hline
\end{tabular}

Section 6: Finally, students indicated where they would prefer to work on completion of their program. Six (37.5\%) students indicated they wanted to work in a private midwifery practice, three $(18.8 \%)$ in a regional hospital and four $(25 \%)$ in a hospital-based MGP. Two students were unsure.

\section{Relationships between constructs of the clinical program}

Relationships between the scales used to evaluate constructs of the clinical program were examined. Tests for homogeneity of variance were not significant for 3 scales, allowing Pearson's correlation to be used. There were significant correlations between perceptions of the caseload model and learning culture $(\mathrm{r}=.871 \mathrm{p}<.001)$ and assessment scales $(\mathrm{r}=.878$ $\mathrm{p}<.001$ ). Spearman's rho (non-parametric) was used for the clinical learning environment scale. Scores on the clinical learning environment scale were significantly positively correlated with perceptions of the caseload model ( $\mathrm{rho}=.868 \mathrm{p}<.001$ ), learning culture (rho $=.949 \mathrm{p}<.001)$ and assessment $($ rho $=.654 \mathrm{p}<.01)$ scales.

\section{Discussion}

This evaluation of an innovative model of clinical learning in midwifery demonstrated a high level of satisfaction by students. In line with existing literature, continuity of care offers experiential learning opportunities, which, when appropriately supported, become significant authentic learning experiences for students (Sweet \& Glover, 2013). This study also confirms 
that $\mathrm{CoC}$ experiences promote the development of partnerships with women, prepares students to work in CoC models, and is highly valued by them. These results align closely with previous research (McLaughlan et al., 2013; Gray et al., 2012; Gray et al., 2013; Aune et al., 2011). CoC experiences embed midwifery student education in the 'real world' of care for women throughout their continuum of care.

Unlike the UK model of caseloading and other $\mathrm{CoC}$ models instituted in Australia, the RPMEP embeds $\mathrm{CoC}$ in all aspects of students' clinical placement. In line with the findings by Sweet and Glover (2013), early and continued exposure to midwifery practice foster students' development of their own personal midwifery identity and philosophy. However, time commitments, and personal and emotional costs of all models also appear significant and worthy of further research.

The results of this study also highlight the importance of a supportive clinical learning environment that emphasises effective two-way communication between all stakeholders. Overall, students felt well supported by their midwifery mentors with a strong sense of mutual respect and relationship equality. Students commented positively on the culture of learning in their clinical placement site, and that their mentor displayed genuine interest in their learning. These findings are in contrast to those of Sweet and Glover (2013) in their study of midwifery students experiences of CoC where students felt isolated from the health care environment and not included in care provision. Research in nursing has shown that the strength of the mentor relationship is one of the most influential elements on student learning and confidence (Gray and Smith, 2000; Randle, 2001; Begley, 2002; Papp et al., 2003). Sweet and Glover (2013) confirm the importance of the mentor relationship in midwifery and highlighted that provision of formative feedback and building stronger relationships with clinicians will improve the likelihood of authentic supported learning. It will require midwifery clinicians and academics working together to enact the midwifery curricula to ensure students use their clinical reasoning and reflection skills to extend their knowledge and understanding. This improved relationship may then afford a greater mutual benefit in service provision and give students' a greater sense of belonging and value in the healthcare team which has also been highlighted in nursing (Levett-Jones and Lathlean, 2008). Importantly, positive mentor relationships can impact confidence levels of graduate midwives (Donovan, 2008).

Students also commented positively about feeling comfortable to ask their midwifery mentors 
questions. Although this finding may appear simplistic, it has significant impact on future midwifery practice and student confidence. Students often have difficulty communicating their learning needs and asking questions as they navigate the complex social environment of the health care system. Henderson et al. (2012) emphasised the importance of fostering inquiry in students to promote contemporary quality practice in the healthcare environment. They suggest that inviting and welcoming questions from students is an important strategy to promote inquiry and critical thinking.

The positive findings related to mentor support may be explained by continuity of placement site where students are more likely to feel a sense of belonging to the team (McKenna et al., 2009; Gilmour et al., 2013). This sense of belonging has a significant impact on student learning, as those students who feel part of a team are more motivated, less anxious, more self-directed in their learning, and display greater confidence (Levett-Jones and Lathlean, 2009a; 2009b). Continuity of midwifery mentorship also impacts on students' ability to work independently. Students report that a mentor's confidence in their abilities is directly proportional to the amount of time spent together (Hughes and Fraser, 2011). Our findings support Gray et al. (2013) who suggested that the ideal learning environment for midwifery students is one where all midwives are committed to teach and facilitate learning, and students are placed with midwives in the same setting over a continuous period of time.

The attitudes and philosophy of the mentor midwife may also impact quality of learning experiences. Students valued and reported enhanced learning opportunities when their mentor practiced with a woman-centred, evidence-based and reflective approach (Hughes and Fraser 2011). With a positive role model as a mentor, students' learning extends from skills, to include professional attitudes and behaviours, further developing the student's own identity as a midwife (Gray et al., 2013). It could be argued that midwives who work in private practice or midwifery group practices have such an approach and this would account for the positive findings related to mentorship in the RPMEP.

Unlike the findings of McLachlan et al. (2013) the RPMEP capitalised on untapped continuity of care options for women. The "prescriptive requirements" regarding the number and hours of follow-through experiences did not present significant challenges for the RPMEP midwifery students. In fact, most students had completed more than their minimum required continuity of care experiences. Previous studies identified that recruiting women 
was a major challenge with CoC experiences (Gray et al., 2013, Gray et al., 2012, McLachlan et al., 2013). RPMEP arrangements whereby students are placed within CoC midwifery models resulted in relatively seamless recruitment of women. Although women are always given the choice regarding student involvement, the presence and involvement of the student is seen as 'standard' practice and they are viewed as part of the midwifery team.

Providing continuity of care also has the potential to disrupt and interfere with academic requirements. In a state-wide survey of midwifery students and academics concerns were raised by both groups regarding meeting university course requirements, including missing lectures/tutorial and clinical placements while students were on call for births (McLaughlan et al., 2013). This was not evident with RPMEP cohort studied as flexible delivery of the degree in which online lectures are recorded, minimises absenteeism. Also RPMEP students are placed in $\mathrm{CoC}$ models and don't 'miss' clinical placement as their $\mathrm{CoC}$ experiences are embedded within their clinical program. Gray et al. (2013) also found that students gained more from the follow-through experience when supported by midwives working alongside them in a continuity model.

Although students in this study felt inspired and fulfilled by a caseload model, and reported positively about learning opportunities and clinical skill enhancement, concerns were raised about their ability to achieve a satisfactory work/life balance within this type of practice. These concerns may be explained by a number of extraneous factors. Several of the private midwifery practices where students were placed were relatively new. The students witnessed business processes of setting up a new practice, securing new premises, administration processes, building clinical capacity, political lobbying and marketing. Although anecdotally students spoke positively about their involvement in developing a private midwifery practice, they witnessed their midwifery mentors work long hours establishing a business, which may have negatively affected their perception of a possible work/life balance. The ability to separate the hours spent on business development to those spent in clinical care has not been obvious to the students involved in this project.

Students generally have little control or involvement over appointment times with women. Generally appointment times are determined to suit both the midwife and the woman, often meaning the student attends appointments at inconvenient times, potentially resulting in wide spread of commitments across the week. In response to this finding, discussions commenced with students regarding the flexibility afforded from working in $\mathrm{CoC}$ models. Two midwives 
who have worked in caseload models recorded an online session for students about the realities of working in caseload practice. In addition, midwifery mentors were invited to attend an on-campus session on sustainability in midwifery CoC models. Further consolidation of these concepts (work/life balance, building resilience) is now addressed within a final capstone course prior to graduation. These strategies are in line with recommendations from Rawnson (2011) regarding the need for effective preparation of students for the realities of caseload practice and the provision of supportive frameworks.

Overall students reported being very satisfied with the learning opportunities and skill development continuity of care provides. Caring for women who are known to students is recognised as situated learning (Gray et al., 2013). Continuity of care experiences can also facilitate a smooth transition to practice. Fenwick et al. (2012) interviewed 16 new midwifery graduates and found that continuity with women enhanced confidence and restored faith in normal birth. This confidence is important as the midwifery culture of some institutions remains highly contested with midwives struggling to provide woman-centred care and are often challenged by the risk-averse nature of maternity care.

\section{Limitations}

Our results need to be considered in light of the limitations. The findings cannot be generalized because of the small sample. However, the majority of students (96\%) participated and there was a high level of agreement amongst respondents in many areas, lending some confidence to the conclusions. The sample size also limited the extent of statistical analysis. Furthermore, this new survey tool needs to be validated with a larger sample. This preliminary work may contribute to the development of standardised measures of students' CoC experiences that can be replicated across settings and provide useful formative and summative data.

\section{Conclusions}

RPMEP students reported positively on the impact of $\mathrm{CoC}$ experiences on their learning, mentor support, relationships with women, and their preparation to work in midwifery $\mathrm{CoC}$ models following graduation. As midwifery continuity models become more prevalent in Australia, clinical placement models need to reflect these practice changes and embed students in continuity, rather offer $\mathrm{CoC}$ as an additional requirement . The unique approach to clinical placement outlined has the potential to build midwifery workforce capacity in $\mathrm{CoC}$ 
models. Strategies that help students achieve work-life balance in caseload midwifery care need to be implemented. 


\section{References}

Australian Health Ministers' Advisory Council, 2011. National Maternity Services Plan: Implementation for the Middle Years, 2012-13. Canberra: Australian Government.

Australian Nursing and Midwifery Council, 2010. Midwives: standards and criteria for the accreditation of nursing and midwifery courses leading to registration, enrolment, endorsement and authorisation in Australia. Canberra, ANMAC.

Aune, I., Dahlberg, U., Inge, O., 2011. Relational continuity as a model of care in practical midwifery studies. British Journal of Midwifery 19, 8, 515-523.

Begley, C. M., 2002. 'Great fleas have little fleas': Irish students' views of the hierarchy in midwifery. Journal of Advanced Nursing, 38, 310-317

Carolan-Olah, M.,Kruger, G. Walter, R. \& Mazzarino, M., (2014) Final year students' experiences of the Bachelor of Midwifery course. Midwifery 30, 5, 519-25.

Clements, V., Davis, D., \& Fenwick, J. H., 2013. Continuity of care: supporting new graduates to grow into confident practitioners. International Journal of Childbirth 3, 1, 312.

Donovan, P., 2008. Confidence in newly qualified midwives. British Journal of Midwifery $16,510-514$.

Fenwick, J., Hammond, A., Raymond, J., Smith, R., Gray, J., Foueur, M., Homer, C., \& Symon, A., (2012). Surviving, not thriving: a qualitative study of newly qualified midwives'. Journal of Clinical Nursing Journal of Clinical Nursing 21, 2054-2063, doi: 10.1111/j.1365-2702.2012.04090.x

Fry, J., Rawnson, S., \& Lewis, P., 2008. Student caseloading: Preparing and supporting students. British Journal of Midwifery 16, 568-573.

Gilmour, C., McIntyre, M., McLelland, G., Hally, H., \& Miles, M., (2013). Exploring the impact of clinical placement models on undergraduate midwifery students. Women \& Birth 26, 1, e21-e25

Gray, J. E., Leap, N., Sheey, A., \& Homer, C. S. E., 2012. The 'follow-through' experience in three-year Bachelor of Midwifery programs in Australia: A survey of students. Nurse Education in Practice 2, 5, 258-263.

Gray, J., Leap, N., Sheey, A., \& Homer, C. S. E., 2013. Students' perceptions of the followthrough experience in 3 year bachelor of midwifery programmes in Australia. Midwifery 29, 4, 400-406.

Gray, M., Smith, L.N., 2000. The qualities of an effective mentor from the student nurse's perspective: findings from a longitudinal study. Journal of Advanced Nursing 32, 15421549 .

Hatem, M., Sandall, J., Devane, D., Solanti, H. and Gates S. (2008) Midwife-led versus other models of care for childbearing women. Cochrane Database of Systematic Reviews, Issue 4. Art No.: CD004667. DOI: 10.1002/14651858.CD004667.pub 2.

Henderson, A., Cooke, M., Creedy, D.K., Walker, R., 2012. Nursing students' perceptions of learning in practice environments: a review. Nurse Education Today 3, 3, 299-302.

Hughes, A. J. \& Fraser D.M., 2011. "There are guiding hands and there are controlling hands"': student midwives experience of mentorship in the UK. Midwifery 27, 4, 477-83. 
Levett-Jones, T., Lathlean, J., 2008. Belongingness: a pre-requisite for nursing students clinical learning. Nurse Education in Practice 8, 103-111. doi:10.1016/ j.nepr.2007.04.003.

Levett-Jones T, Lathlean J., 2009a. The Ascent to Competence Conceptual framework: an outcome of a study of belongingness. Journal of Clinical Nursing 18, 20, 2870-9.

Levett-Jones T, Lathlean J., 2009b. 'Don't rock the boat': nursing students' experiences of conformity and compliance. Nurse Education Today, 29, 3, 342-9.

Lewis, P., Fry, J., Rawson, S., 2008. Student midwife caseloading - a new approach to midwifery education. British Journal of Midwifery 16, 8, 499-503.

McKenna, L., \& Rolls, C., 2007. Bachelor of Midwifery: Reflections on the first 5 years from two Victorian universities. Women and Birth 20, 2, 81-84. doi:10.1016/j.wombi.2007.04.002.

McKenna, L., Wray, N. \& McCall, L., 2009. Exploring continuous clinical placement for undergraduate students. Advances in Health Sciences Education, 14, 3, 327-335.

McLachlan, H. L., Newton, M., Nightingale, H., Morrow, J., \& Kruger, G., 2013. Exploring the 'follow-through experience': A statewide survey of midwifery students and academics conducted in Victoria, Australia. Midwifery 29, 9, 1064-1072.

Papp, I., Markkanen, M., \& Von Bonsdorff, M., 2003. Clinical learning environment as a learning environment: student nurses' perceptions concerning clinical learning experiences. Nurse Education Today 23, 262-268.

Randle, J., 2001. The effect of a 3 year pre-registration course on students' self-esteem. Journal of Clinical Nursing 10, 293-300.

Rawnson, S., Fry, J., \& Lewis, P., 2008. Student caseloading: embedding the concept within education. British Journal of Midwifery 16, 10, 636-641.

Rawnson, S., Brown, S., Wilkins, C., Leamon, J., 2009. Student midwives' views of caseloading: The BUMP study. British Journal of Midwifery, 17, 8, 484-489.

Rawnson, S., 2011. A qualitative study exploring student midwives' experiences of carrying a caseload as part of their midwifery education in England. Midwifery, 7, 6, 786-792.

Sandall, J., Soltani, H., Gates, S., Shennan, A., Devane, D., 2013. Midwife-led continuity models versus other models of care for childbearing women. Cochrane Database of Systematic Reviews 2013, Issue 8. Art. No.: CD004667. doi: 10.1002/14651858.CD004667.pub3.

Seibold, C., 2005. The experiences of a first cohort of Bachelor of Midwifery students, Victoria, Australia. Australian Midwifery 18, 3, 9-16. doi:10.1016/s14488272(05)80024-0.

Sidebotham, M., Fenwick J., Carter A., \& Gamble, J. 2015. Using the five senses framework to understand the experiences of midwifery students enrolled in an undergraduate degree program. Midwifery 31, 1, 201-207. doi:10.1016/j.midw.2014.08.007

Sweet, L.P. \& Glover P., 2013. An exploration of the midwifery continuity of care program at one Australian University as a symbiotic clinical education model. Nurse Education Today 33, 3, 262-267. 